\title{
RESPIRAÇÃO BASAL DO SOLO SUBMETIDA A DOSES CRESCENTES DE COMPOSTO ORGÂNICO
}

\author{
Kátia Cristina da Silva ${ }^{1}$ \\ Cleicimar Gomes Costa ${ }^{2}$ \\ Vinícius Faúla Aguiar ${ }^{3}$ \\ Luiz Carlos Gomes de Azevedo ${ }^{4}$ \\ Alisson José Eufrásio de Carvalho ${ }^{5}$
}

Resumo: O objetivo do presente trabalho foi avaliar a atividade microbiana, por meio da respiração basal

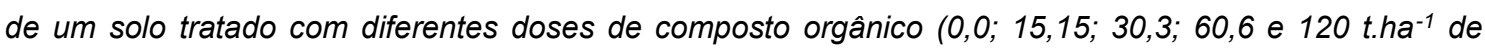
matéria seca). O delineamento experimental utilizado foi o de blocos casualizados. $O$ experimento foi conduzido no IFMG-Campus São João Evangelista-MG. As amostras de solo foram coletadas e levadas ao laboratório para determinação da atividade da biomassa microbiana, sendo umedecidas à capacidade de campo $60 \%$, em seguida acondicionadas em um pote de $500 \mathrm{ml}$ hermeticamente fechado, e incubadas por $72 \mathrm{~h}$ com temperatura de $25^{\circ} \mathrm{C}$. Após esse período as amostras foram tituladas com $\mathrm{HCl} 0,1 \mathrm{~mol} \mathrm{~L}^{-1}$ até o ponto de viragem (mudança da cor branca para cor rósea), anotando-se o volume gasto. Verificou-se que a taxa de liberação $\mathrm{C}-\mathrm{CO}_{2}$ foi crescente em relação às doses de composto aplicadas.

Palavras-chave: Atividade microbiana; Resíduo orgânico; Respiração basal.

\footnotetext{
${ }^{1}$ Bacharelado em Agronomia/ Instituto Federal de Educação Ciência e Tecnologia de Minas Gerais - Campus São João Evangelista - MG, Brasil. E-mail: katiaeaf@yahoo.com.br.

${ }^{2}$ Bacharelado em Agronomia/ Instituto Federal de Educação Ciência e Tecnologia de Minas Gerais - Campus São João Evangelista - MG, Brasil. E-mail: cleicimar_gomesje@hotmail.com.

${ }^{3}$ Bacharelado em Agronomia/ Instituto Federal de Educação Ciência e Tecnologia de Minas Gerais - Campus São João Evangelista - MG, Brasil. E-mail: vinicius.aguiar.agr@gmail.com.

${ }^{4}$ Bacharelado em Agronomia/ Instituto Federal de Educação Ciência e Tecnologia de Minas Gerais - Campus São João Evangelista - MG, Brasil. E-mail: luizcap2011@hotmail.com.

${ }^{5}$ Bacharelado em Agronomia/ Instituto Federal de Educação Ciência e Tecnologia de Minas Gerais - Campus São João Evangelista - MG, Brasil. E-mail: alisson.carvalho@ifmg.edu.br.
} 